\title{
ERRATA
}

\section{Rapid Identification of Fungi by Using the ITS2 Genetic Region and an Automated Fluorescent Capillary Electrophoresis System}

CHRISTINE Y. TURENNE, STEVEN E. SANCHE, DARYL J. HOBAN, JAMES A. KARLOWSKY AND AMIN M. KABANI

Department of Medical Microbiology, Faculty of Medicine and Faculty of Pharmacy, University of Manitoba, and Departments of Clinical Microbiology and Medicine, Health Sciences Centre, Winnipeg, Manitoba R3A 1R9,

Canada, and Division of Infectious Diseases, Royal University Hospital, Saskatoon, Saskatchewan, Canada

Volume 37, no. 6, p. 1846-1851, 1999. Page 1847, column 2, line 8: The sequence for primer ITS4 should read 5'-tcc tcc gct tat tga tat gc-3'.

\section{Acute-Phase-Specific Hepatapeptide Epitope for Diagnosis of Parvovirus B19 Infection \\ LEENA KAIKKONEN, HILKKA LANKINEN, IRENE HARJUNPÄÄ, KATI HOKYNAR, MARIA SÖDERLUND-VENERMO, CHRISTIAN OKER-BLOM, LEA HEDMAN, AND KLAUS HEDMAN \\ Department of Virology, Haartman Institute and HUCH Diagnostic, University of Helsinki, Helsinki, and VTT Biotechnology and Food Research, VTT, Espoo, Finland}

Volume 37, no. 12, p. 3952-3956, 1999. Page 3955, Fig. 4 legend: “(ETS ratio, 1.3)” should read “(ETS ratio, 11.3).” 